\title{
A Review of the Scaling Study of the CANDU-6 Moderator Circulation Test Facility
}

\author{
Bo Wook Rhee, Hyoung Tae Kim \\ Severe Accident and PHWR Safety Research Division, Korea Atomic Energy Research Institute (KAERI), Daejeon, \\ Republic of Korea \\ Email: bwrhee@kaeri.re.kr
}

Received July 2014

\section{Abstract}

Following the previous relevant works [1]-[3], a scaling analysis is performed to derive a set of scaling criteria which were thought to be suitable for reproducing the major thermal-hydraulic phenomena in a scaled-down CANDU moderator tank similar to that in a prototype power plant during a full power steady state condition. The objective of building a scaled-down moderator tank is to generate the experimental data necessary to validate the computer codes which are used to analyze the accident analysis of CANDU- 6 plants. The major variables of interests in this paper are moderator flow velocity and temperature of the moderator which is $D_{2} \mathrm{O}$ inside the moderator tank during a steady state and transient conditions. The reason is that the local subcooling of the moderator is found to be a critical parameter determining whether the stable film boiling can sustain on the outer surface of the calandria tube if the contact of overheated pressure tube and cold calandria tube should occur due to pressure tube ballooning during LBLOCA with ECC injection failure [4]. The key phenomena involved include the inlet jet development and impingement, buoyancy force driven by the moderator temperature gradient caused by non-uniform direct heating of the moderator, and the pressure drop due to viscous friction of the flow across the calandria tube array. In this paper, the previous researches are reviewed, some concerns or potential problems associated with them implied by comparing CFD analyses results between the CANDU-6 moderator tank and 1/4 scaled-down test facility are described, and as a way to examine the assumption of the scaling analysis is true an order-of-magnitude analyses are performed. Based on the results of these analyses the assumption of neglecting $\left(\nabla^{*}\right)^{2} \mathbf{V}^{*}$ and $\left(\nabla^{*}\right)^{2} \mathbf{T}^{*}$ terms cannot be justified for the power of $0.5 \mathrm{MW}$ and $1.566 \mathrm{MW}$ for the $1 / 4$ scaled-down facility. Further investigation is thought to be necessary to confirm this result, i.e. if the scaling of the previous work1 is justifiable by some other independent analyses.

\section{Keywords}

CANDU-6, Thermal-Hydraulic Phenomena, Moderator Tank, Experimental Test Facility, Scaling Analysis 


\section{Introduction}

In order for a computer code to be qualified to predict the local subcooling of the moderator during major DBAs in CANDU-6 reactor for licensing application, it is necessary to have enough experimental data appropriate to validate the computer code. As most of the experimental data relevant to moderator circulation and temperature of a CANDU-6 reactor are restricted for either publication or sharing through IAEA/OECD-NEA due to the proprietary nature, it was hard for Korean $R \& D$ institutes to acquire the experimental data necessary to validate their computer codes for moderator circulation and subcooling analyses of CANDU-6 plants. Thus it was decided to erect an experimental test facility from which the experimental data necessary to validate the computer codes for moderator circulation and subcooling analyses for licensing application as a part of the medium and long range nuclear R\&D program. For this purpose a scaling study of the moderator circulation of a CANDU-6 reactor started at KAERI.

According to the literature survey, several scaling studies have been performed to derive a set of scaling criteria which were thought to be suitable for reproducing the major thermal-hydraulic phenomena in a scaled-down CANDU moderator tank similar to that in a prototype power plant during a full power steady state condition. The major variables of interests in these papers are moderator flow velocity and temperature of the moderator which is $\mathrm{D}_{2} \mathrm{O}$ inside the moderator tank during a steady state and transient conditions. The reason is that the local subcooling of the moderator is found to be a critical parameter determining whether the stable film boiling can sustain on the outer surface of the calandria tube if the contact of overheated pressure tube and cold calandria tube should occur due to pressure tube ballooning during LBLOCA with ECC injection failure. The key phenomena involved include the inlet jet development and impingement, buoyancy force driven by the moderator temperature gradient caused by non-uniform direct heating of the moderator, and the pressure drop due to viscous friction of the flow across the calandria tube array.

\section{CANDU-6 Moderator Circulation Test Facility Scaling Strategy of KAERI}

\subsection{Rationale of Scaling Study up to Now}

In this study the governing equations were transformed into dimensionless equations based on the representative characteristic values of the basic design such as the time, tank diameter, inlet jet velocity, and the moderator temperature rise across the tank. Then 3 dimensionless numbers, Re, Pr, Ar, were identified as those characterizing the key phenomena of the system. The relevant boundary conditions were then identified in a dimensionless form, and the compatibility of keeping these 3 dimensionless numbers, the volumetric heat source distribution, and the boundary conditions in dimensionless forms the same for both the prototype and scale-down tanks were examined, and some of them that are judged to be less important are relaxed so as to find a practically implementable set of constraints. The size of the scaled-down moderator tank and corresponding inlet jet velocity are then found for the available power supply size. As an example, an analysis was performed for a power supply capacity of 1.566 MW and 0.5 MW as compared to 100MW for the prototype.

\subsection{Attempts to Prove the Validity of Scaling Study}

As a way to confirm the validity of the current work two numerical CFD simulations were carried out with the boundary conditions at the inlet and outlet ports, and on the walls of the solid structures, such as the moderator tank and calandria tubes, which were derived from those of the dimensionless scales to check if the moderator flow and temperature patterns of both the prototype reactor and scaled-down facilities are identical or at least similar. A steady-state solution is first obtained for the CANDU-6 reactor normal operation. Similar simulation was done for the scaled-down facility and results presented. Comparison results are discussed, and the cause of the potential distortion of the scaling owing to practical limitations and possible solutions is finally discussed.

\section{Derivation of Dimensionless Governing Equations and Boundary}

\subsection{Dimensionless Governing Equations and Boundary}

$$
\begin{aligned}
& \nabla \cdot \mathrm{V}=0 \\
& \frac{\partial \mathrm{V}}{\partial \mathrm{t}}+(\mathrm{V} \cdot \nabla) \mathrm{V}=-\frac{1}{\rho_{\text {ref }}} \nabla \mathrm{P}+\frac{\mu}{\rho_{\text {ref }}} \nabla^{2} \mathrm{~V}+\mathrm{g}\left(\frac{\rho-\rho_{\text {ref }}}{\rho_{\text {ref }}}\right)
\end{aligned}
$$




$$
\frac{\partial \mathrm{T}}{\partial \mathrm{t}}+(\mathrm{V} \cdot \nabla) \mathrm{T}=\frac{\mathrm{k}}{\rho_{\text {ref }} \mathrm{C}_{\mathrm{p}}} \nabla^{2} \mathrm{~T}+\frac{\mathrm{q}}{\rho_{\text {ref }} \mathrm{C}_{\mathrm{p}}}
$$

According to a previous study by Khartabil [1], the dimensionless variables can be defined as below,

$$
\begin{aligned}
& \mathrm{V}^{*}=\mathrm{V} / U_{\mathrm{i}}, \mathrm{T}^{*}=\left(\mathrm{T}-\mathrm{T}_{\text {sat }}\right) / \Delta \mathrm{T}, \mathrm{P}^{*}=\mathrm{P} /\left(\rho_{\text {ref }} U_{\mathrm{i}}^{2}\right) \\
& \mathrm{t}^{*}=t U_{\mathrm{i}} / \mathrm{D}, \nabla^{*}=\mathrm{D} \nabla, \quad \mathrm{Re}=\rho_{\text {ref }} U_{\mathrm{i}} \mathrm{D} / \mu \\
& \mathrm{Pr}=\mu \mathrm{C}_{\rho} / \mathrm{k}, \quad \mathrm{Ar}=\mathrm{g} \beta_{\text {ref }}\left(\mathrm{T}-\mathrm{T}_{\mathrm{i}}\right) \mathrm{D} / U_{\mathrm{i}}^{2} \\
& \mathrm{q}^{*}=\frac{\mathrm{q}(\mathrm{x}, \mathrm{y}, \mathrm{z}, \mathrm{t}) d_{h}}{\rho_{\text {ref }} \mathrm{C}_{\mathrm{p}} U_{\mathrm{i}} \Delta \mathrm{T}}, \Delta \mathrm{T}=\left(\mathrm{T}_{\mathrm{o}}-\mathrm{T}_{\mathrm{i}}\right)
\end{aligned}
$$

The following dimensionless governing equations can then be derived

$$
\begin{gathered}
\nabla^{*} \mathrm{~V}^{*}=0 \\
\frac{\vartheta \mathrm{V}^{*}}{\vartheta \mathrm{t}^{*}}+\left(\nabla^{*} \mathrm{~V}^{*}\right) \mathrm{V}^{*}=-\nabla^{*} \mathrm{P}^{*}+\frac{1}{\operatorname{Re}}\left(\nabla^{*}\right)^{2} \mathrm{~V}^{*}-\operatorname{Ar} \frac{\mathrm{g}}{|\mathrm{g}|} \mathrm{T}^{*} \\
\frac{\vartheta \mathrm{T}^{*}}{\vartheta \mathrm{T}^{*}}+\left(\mathrm{V}^{*} \nabla^{*}\right) \mathrm{T}^{*}=\frac{1}{\operatorname{Re} \operatorname{Pr}}\left(\nabla^{*}\right)^{2} \mathrm{~T}^{*}+\mathrm{q}^{*}
\end{gathered}
$$

Boundary Conditions:

- on a fixed solid surface (in case of wall heating):

$$
\mathrm{V}^{*}=0, \mathrm{q}^{* * *}=\mathrm{q}_{w}^{\prime * *}
$$

- at an inlet or outlet: Known $\mathrm{V}^{*}, \mathrm{~T}^{*}$ or $\mathrm{P}^{*}$.

\subsection{Conflict between Re and Ar Similarity}

If the same working fluid is used for both the prototype and the scaled-down facilities Pr can be considered nearly uniform inside the tank. Also Re and Ar will depend on $\Delta \mathrm{T}, \mathrm{U}_{\mathrm{i}}$, and $\mathrm{D}$. Therefore, if any combination of $\Delta \mathrm{T}, \mathrm{U}_{\mathrm{i}}$, and $\mathrm{D}$ for which $\mathrm{Re}, \mathrm{Ar}$, and the dimensionless volumetric heat source, $\mathrm{q}^{*}$, may be kept the same for both facilities, the hydrodynamic similarity inside the moderator tank is maintained. However, in practice, maintaining both Re and Ar the same for the prototype tank and the scaled-down tank turns out to be impossible as the tank dimension for the scaled-down tank becomes larger than the prototype tank dimension. Maintaining similarity in Re is not possible because of the need for a reduced tank size. According to Khartabil's argument [1], the impact of abandoning the Reynolds number equivalence is that the relative contributions of the momentum and energy diffusion by molecular motion are not the same between the prototype and scaled-down facility, and by ensuring a turbulent flow prevail throughout the tank, the relative contributions of these diffusion processes represented by the Laplace operator on $\mathrm{V}^{*}$ and $\mathrm{T}^{*}$ to the overall balances in Equations (1) and (2) can be neglected. Thus, if Re is large enough to guarantee a turbulent flow throughout the moderator tank for both facilities, it can be justified that the overall similarity for both the prototype and scaled-down tanks be reasonably kept. However how can it be ensured for the flow inside the tank, including the inner tube bank region during steady as well as transient conditions remains questionable. To confirm if this turbulence assumption is true or not, one would need to perform CFD analyses for both the prototype and scaled-down facilities for the normal steady state conditions

\subsection{Determination of the Operating Conditions Using the Ar Similarity}

If the argument of Khartabil is assumed to be true, one then only needs to be concerned how to keep Ar and $\mathrm{q}^{*}$ the same for both the prototype and scaled down tanks.

$$
\frac{\Delta \mathbf{T}_{\mathbf{m}}}{\Delta \mathbf{T}_{\mathbf{P}}}=\left(\frac{\mathbf{U}_{\mathrm{i}, \mathrm{m}}}{\mathbf{U}_{\mathrm{i}, \dot{\mathrm{P}}}}\right)^{2}\left(\frac{\mathbf{D}_{\mathbf{P}}}{\mathbf{D}_{\mathbf{m}}}\right) \frac{\boldsymbol{\beta}_{\mathbf{P}}}{\boldsymbol{\beta}_{\mathbf{m}}}
$$


However, $\Delta \mathrm{T}_{\mathrm{m}} / \Delta \mathrm{T}_{\mathrm{P}}$ cannot be determined arbitrarily, but needs to be subject to another constraint of the capacity of the power supply,

$$
\iiint \mathrm{q}_{\mathrm{m}}(\mathrm{x}, \mathrm{y}, \mathrm{z}, \mathrm{t}) \mathrm{dV}=\mathrm{Q}_{\mathrm{m}},
$$

and the heat source distribution similarity condition or dimensionless volumetric heat source, as claimed by Khartabil [1],

$$
\frac{q_{p}(x, y, z, t) D_{p}}{\left(\rho_{\text {ref }} C_{p} U_{i} \Delta T\right)_{p}}=\frac{q_{m}(x, y, z, t) D_{m}}{\left(\rho_{\text {ref }} C_{p} U_{i} \Delta T\right)_{m}}
$$

The integration of these dimensionless volumetric heat sources over the whole dimension less tank volume of each facility is necessary for the closure of the equations.

If both sides of this equation are integrated over the relevant space domains, we obtain another constraint as below:

$$
\frac{Q_{p}}{\left(\rho_{\text {ref }} C_{p} U_{i} \Delta T\right)_{P} D_{P}{ }^{2}}=\frac{Q_{m}}{\left(\rho_{\text {ref }} C_{p} U_{i} \Delta T\right)_{m} D_{m}{ }^{2}}
$$

Thus, if Equation (4) is inserted into Equation (3), one can obtain

$$
\frac{\mathbf{Q}_{\mathbf{P}}}{\mathbf{Q}_{\mathbf{m}}}=\frac{\left(\rho C_{p}\right)_{P}}{\left(\rho C_{p}\right)_{m}}\left(\frac{D_{P}}{D_{m}}\right)\left(\frac{\boldsymbol{\beta}_{\mathbf{m}}}{\boldsymbol{\beta}_{\mathbf{p}}}\right)\left(\frac{U_{i, P}}{U_{i, m}}\right)^{3}
$$

From this equation, one can determine the ratio of the inlet average velocity once the heat load ratio and geometry scale are fixed. This inlet average velocity ratio in turn is determined $\left(\frac{\Delta \mathrm{T}_{\mathrm{m}}}{\Delta \mathrm{T}_{\mathrm{p}}}\right)$ from Equation (3). If $\Delta \mathrm{T}_{\mathrm{m}}$ and $D_{m}$ are acceptable from the viewpoints of coolant temperature measurement accuracy and the space available for the instruments installation and probe accessibility, one can fix this combination of Q, D and $\Delta \mathrm{T}$.

(1) Power Supply of 0.5 MW Case

The power supply of the scaled-down moderator tank is $500 \mathrm{~kW}$, and the diameter is fixed to be $1.9 \mathrm{~m}$ and the length is $1.5 \mathrm{~m}$, which is $1 / 4$ of the prototype tank. If these values are inserted into Equation (4) and $\boldsymbol{\rho}_{\text {ref }} \mathbf{C}_{\mathbf{p}}$ assumed the same one obtains

$$
\left(\frac{U_{i, P}}{U_{i, m}}\right)=3.956 .
$$

As the inlet nozzle velocity of the prototype, $U_{i, P}$, is $2.05 \mathrm{~m} / \mathrm{s}, U_{i, m}$ becomes $0.518 \mathrm{~m} / \mathrm{s}$.

(2) Power Supply of 1.566 MW Case

The power supply of the scaled-down moderator tank is $1.566 \mathrm{~W}$, and the inlet nozzle velocity can be found to be $U_{i, m}$ becomes $0.7583 \mathrm{~m} / \mathrm{s}$.

\section{CFD Analysis for Both Power Cases}

A steady-state solution is first obtained for normal reactor operation prior to the transient or accident using the mesh grid configuration shown in Figure 1 using a computer code, MODTURC_CLAS [3] for a full power operating condition as shown in Table 1, where a moderator heat load of $100 \mathrm{MW}$, a total inlet flow of $940 \mathrm{l} / \mathrm{s}$ or equivalently $1016 \mathrm{~kg} / \mathrm{s}$ and outlet temperature of $69^{\circ} \mathrm{C}$ as design values and the steady-state simulation shows the maximum temperature in the moderator core region of $84^{\circ} \mathrm{C}$, while the bulk average temperature is $74.3^{\circ} \mathrm{C}$, as shown in Figure 2.

The steady state operating of the scaled-down test facility as determined $1 / 4$ of the prototype reactor is simulated using the grid structure as shown in Figure 3. For the simplicity only a right half of the total tank is simulated while the whole circular domain of the tank is simulated. Note that the grid structure of the circular planes at various axial locations is different from that of the prototype reactor. The reason is because the CFD computer code used for this analysis is an in-house computer code developed at KAERI for past several years, and due to its restriction on the grid generation, a grid structure as shown in the right side of Figure $\mathbf{3}$ is used. The steady 


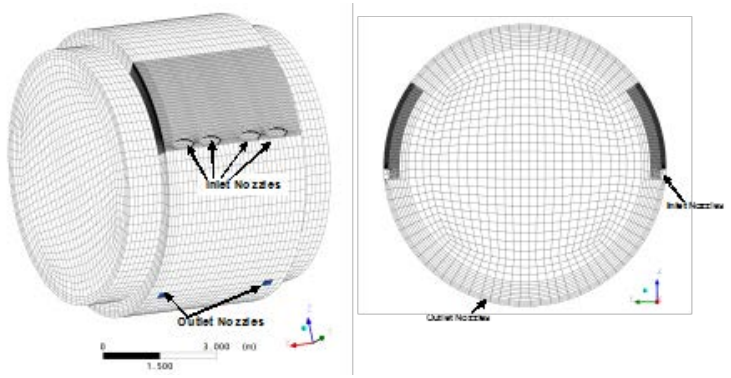

Figure 1. 3-dimensional grid configuration.

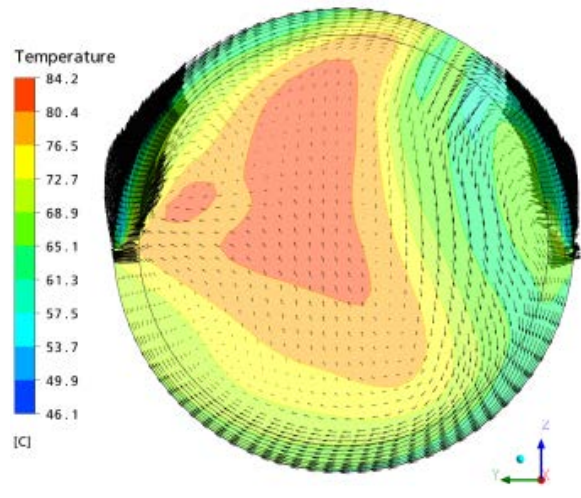

(a) $\mathrm{x}=3.0 \mathrm{~m}$

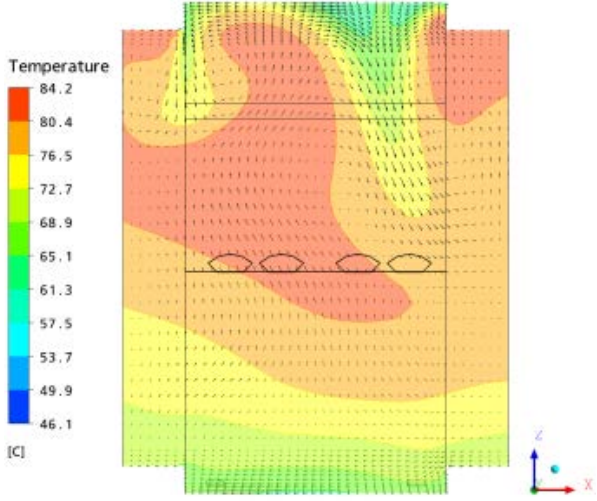

(b) $\mathrm{y}=0.0 \mathrm{~m}$

Figure 2. Moderator velocity and temperature distribution under a full power steady state.
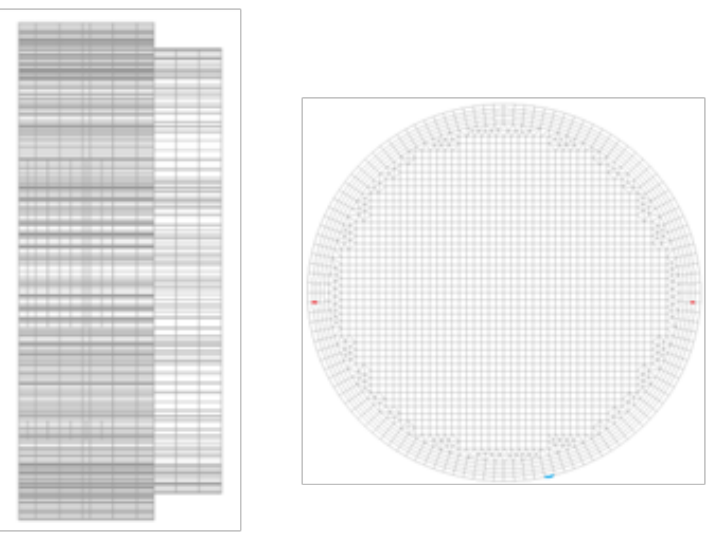

Figure 3. 3-D grid configuration for scaled-down facility.

Table 1. CANDU-6 moderator tank operating condition.

\begin{tabular}{lc}
\hline Parameter & Values \\
\hline Moderator tank thermal load & $100 \mathrm{MW}$ \\
Exit temperature & $70.6^{\circ} \mathrm{C}$ \\
Inlet mass flow rate & $1016 \mathrm{~kg} / \mathrm{s}$ \\
Fractional inlet mass flow rate ratio (Left:Right) & $49: 51$ \\
\hline
\end{tabular}

state operating condition is summarized in Table 2 for the 1/4 scaled-down test facility. The analysis result is shown in Figure 4 and Figure 5. 
Table 2. Scaled-down moderator tank operating condition at full power steady state.

\begin{tabular}{lc}
\hline Parameter & Values \\
\hline Moderator tank thermal load & $500 \mathrm{~kW}$ \\
Exit temperature & $47.3^{\circ} \mathrm{C}$ \\
Inlet Mass flow rate & $17.287 \mathrm{~kg} / \mathrm{s}$ \\
Fractional inlet mass flow rate ratio (Left:Right) & $49: 51$ \\
\hline
\end{tabular}

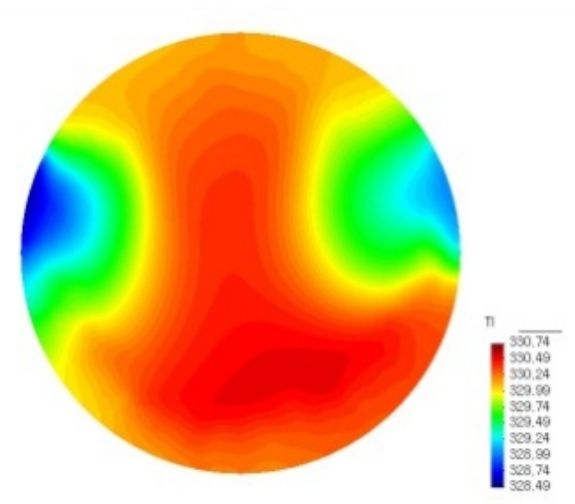

(a) Temperature at the plane where exit port locates

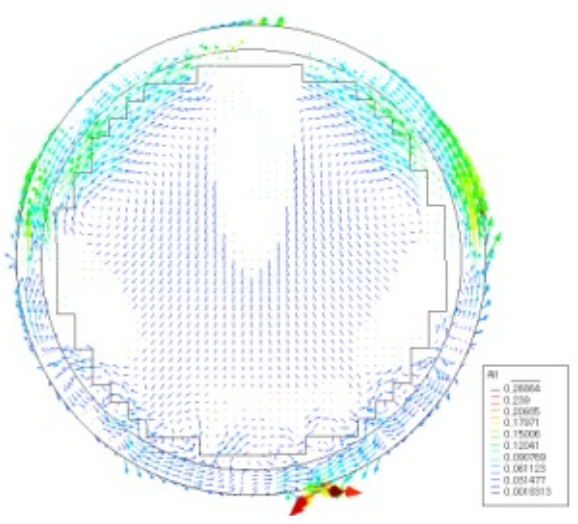

(b) Velocity at the plane where exit port locates

Figure 4. Moderator temperature and velocity distribution at the cross section where inlet and exit ports are located at full power steady state (1/4 scaled-down facility).
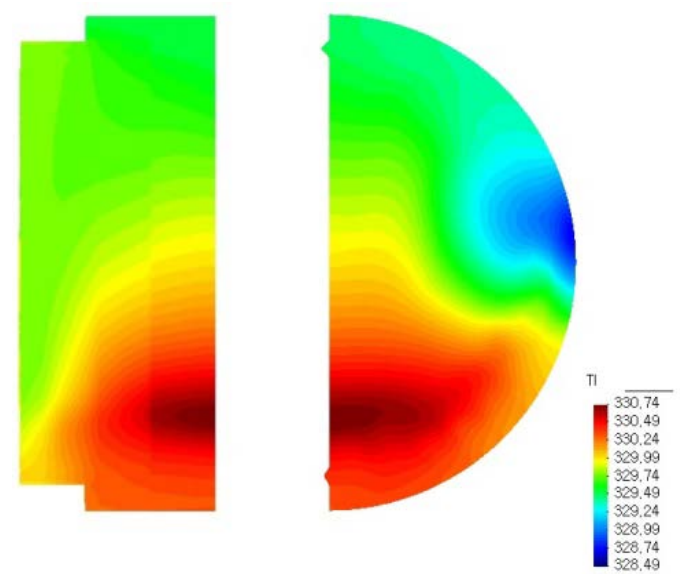

Figure 5. Moderator temperature distribution at full power steady state (1/4 scaled-down facility).

\section{Order of Magnitude Analysis}

To examine if the argument that if Re is large enough to guarantee a turbulent flow throughout the moderator tank for both facilities, it can be justified that the overall similarity for both the prototype and scaled-down tanks be reasonably kept is valid or not, an order of magnitude analysis is performed for both CANDU-6 full power steady state and $1 / 4$ scaled-down moderator tanks. The thermal power of the scaled-down tank is both $500 \mathrm{~kW}$ and $1566 \mathrm{kw}$ cases.

\subsection{CANDU-6 Full Power Steady State}

$\mathrm{D}=7.6 \mathrm{~m}$, Pitch $=0.286 \mathrm{~m}$ 


$$
\begin{aligned}
& \mathrm{u}_{\mathrm{i}}=2.043 \mathrm{~m} / \mathrm{sec}, \quad \rho_{f}=1085 \mathrm{~kg} / \mathrm{m}^{3} \\
& \mu=0.00055 \mathrm{~kg} / \mathrm{m} \cdot \mathrm{s}, \quad \mathrm{T}_{\text {out }}=70.6^{\circ} \mathrm{C} \mathrm{T}_{\text {in }}=47.274^{\circ} \mathrm{C} \\
& \operatorname{Pr} \approx 1 \\
& \mathrm{D}_{\mathrm{h}}=0.138 \mathrm{~m} \\
& \mathrm{~T}_{\text {ref }}=\frac{3 T_{\text {in }}-T_{\text {out }}}{2} \\
& \mathrm{~V}=0.5 \mathrm{~m} / \mathrm{sec} \text { (assumed) } \\
& \nabla^{*}=\frac{\mathrm{Dd} \delta}{\mathrm{dx}}=\frac{D}{\text { Pitch }}=26.573 \\
& \mathrm{~V}^{*}=\frac{v}{u_{i}}=0.245 \\
& \left(\nabla^{*}\right)^{2} V^{*}=172.796 \\
& \operatorname{Re}=\frac{\rho_{f} U_{\mathrm{i}} D_{h}}{\mu}=5.567 \times 10^{5} \\
& T^{*}=\frac{T-T_{\text {ref }}}{T_{\text {out }}-T_{\text {in }}} \Rightarrow 0.5 \leq T^{*} \leq 2 \\
& T_{\text {in }} \leq T \leq T_{\max }\left(\frac{3 T_{\text {out }}-T_{\text {in }}}{2}\right) \\
& \Delta \mathrm{T}=23.33^{\circ} \mathrm{C}, \quad T \cong \frac{1}{2}\left(T_{\text {in }}+T_{\text {out }}\right)=70.6 \\
& T^{*} \cong 3.03 \\
& \frac{1}{\operatorname{Re}}\left(\nabla^{*}\right)^{2} V^{*}=3.104 \times 10^{-4} \\
& \operatorname{Ar} \cdot T^{*}=0.208 \times T^{*} \approx 0.6302 \\
& \frac{1}{\operatorname{Re}}\left(\nabla^{*}\right)^{2} V^{*}=0.00384 \text {. } \\
& \text { Thus } \frac{1}{\operatorname{Re}}\left(\nabla^{*}\right)^{2} V^{*} \ll \operatorname{Ar} \cdot T^{*} \text {. }
\end{aligned}
$$

Now, look into the energy equation,

$$
\begin{gathered}
q^{*}=q^{\prime \prime \prime *} \frac{D}{\rho_{f} C_{p} U_{\mathrm{i}} \Delta T}=0.013 \\
\frac{1}{\operatorname{Re}}\left(\nabla^{*}\right)^{2} T^{*} \approx 3.84 \times 10^{-3}
\end{gathered}
$$

Therefore, $q^{*} \gg \frac{1}{\operatorname{Re}}\left(\nabla^{*}\right)^{2} T^{*}$

i.e., the $2^{\text {nd }}$ term in the RHS of the dimensionless energy equation is negligible.

\subsection{1/4 Scaled-Down Tank with 0.5 MW Case}

$\mathrm{D}=1.9 \mathrm{~m}$, Pitch $=0.072 \mathrm{~m}, \quad u_{i}=0.519 \mathrm{~m} / \mathrm{sec}$

$\rho_{f}=992.63 \mathrm{~kg} / \mathrm{m}^{3} \quad \mu=0.00055 \mathrm{~kg} / \mathrm{m} \cdot \mathrm{s}$

$T_{\text {out }}=43^{\circ} \mathrm{C}, T_{\text {in }}=35^{\circ} \mathrm{C}, \operatorname{Pr} \approx 1$

$D_{h}=\frac{1}{4}(0.138)=0.0345$ 
$T_{\text {ref }}=\frac{3 T_{\text {in }}-T_{\text {out }}}{2}$

$\mathrm{V}=0.1 \mathrm{~m} / \mathrm{sec}$ (assumed) $\nabla^{*}=\frac{D}{\text { Pitch }}=\frac{1.9}{0.072}=26.573\left(=\frac{1.9}{0.0715}\right)$

$\mathrm{V}^{*}=\frac{v}{u_{i}}=\frac{0.1}{0.519}=0.193$

$\left(\nabla^{*}\right)^{2} V^{*}=136.1$

$\operatorname{Re}=3.233 \times 10^{4}$

$\frac{1}{\operatorname{Re}}\left(\nabla^{*}\right)^{2} V^{*}=4.209 \times 10^{-3}$

$\mathrm{Ar} \cdot \mathrm{T}^{*}=0.208 \times T^{*} \approx 0.208$

$T^{*} \triangleq \frac{T}{\Delta T} \Delta T=8$

$T \cong \frac{1}{2}\left(T_{\text {in }}+T_{\text {out }}\right)=39^{\circ} \mathrm{C}, T^{*}=\frac{39}{8}=4.875$

$\therefore \frac{1}{\operatorname{Re}}\left(\nabla^{*}\right)^{2} T^{*}=\frac{(26.573)^{2}(4.875)}{3.233 \times 10^{4}}=0.1065$

$q^{*}=q^{\prime \prime * *} \frac{D}{\rho_{f} C_{p} u_{i n} \Delta T}$

$q^{*}=\frac{\left(\frac{Q}{\nabla}\right) \cdot D}{\rho C_{p} U_{\mathrm{i}} \Delta T}=0.0112$

$\frac{1}{\operatorname{Re}}\left(\nabla^{*}\right)^{2} T^{*} \approx 0.1065$

$\therefore \frac{q^{*}}{\frac{1}{\operatorname{Re}}\left(\nabla^{*}\right)^{2} T^{*}}=\frac{0.0112}{0.1065}=0.1055$

$q^{*} \approx\left(\nabla^{*}\right)^{2} T^{*}$

Therefore the $2^{\text {nd }}$ term in the RHS of the dimensionless energy equation cannot be neglected.

\subsection{1/4 Scaled-Down Tank with 1.566 MW Case}

$\mathrm{D}=1.9 \mathrm{~m}$, Pitch $=0.072 \mathrm{~m}, u_{i}=0.8055 \mathrm{~m} / \mathrm{sec}$

$\rho_{f}=992.63 \mathrm{~kg} / \mathrm{m}^{3}, \mu=0.00055 \mathrm{~kg} / \mathrm{m} \cdot \mathrm{s}$

$T_{\text {out }}=49.7^{\circ} \mathrm{C}, T_{\text {in }}=35^{\circ} \mathrm{C}, \quad \operatorname{Pr} \approx 1$

$\mathrm{V}=0.1 \mathrm{~m} / \mathrm{sec}$ (assumed)

$\nabla^{*}=\frac{D}{\text { Pitch }}=\frac{1.9}{0.072}=26.573$

$\mathrm{V}^{*}=\frac{v}{u_{i}}=0.124$

$\left(\nabla^{*}\right)^{2} V^{*}=87.66$

$\operatorname{Re}=5.0154 \times 10^{4}$

$\frac{1}{\operatorname{Re}}\left(\nabla^{*}\right)^{2} V^{*}=1.75 \times 10^{-3}$ 


$$
\begin{aligned}
& A r \cdot T^{*}=0.208 \times T^{*} \approx 0.208 \\
& T^{*} \triangleq \frac{T}{\Delta T} \Delta T=14.7^{\circ} \mathrm{C} \\
& T \cong \frac{1}{2}\left(T_{\text {in }}+T_{\text {out }}\right)=42.35^{\circ} \mathrm{C}, \\
& \quad \text { Thus, } T^{*}=\frac{42.35}{14.7}=2.88 \\
& \therefore \frac{1}{\operatorname{Re}}\left(\nabla^{*}\right)^{2} T^{*}=\frac{(26.573)^{2}(2.88)}{5.0154 \times 10^{4}}=0.0405 \\
& q^{*}=q^{\prime \prime \prime *} \frac{D}{\rho_{f} C_{p} U_{\mathrm{i}} \Delta T} \\
& q^{*}=\frac{\left(\frac{Q}{\nabla}\right) \cdot D}{\rho C_{p} U_{\mathrm{i}} \Delta T}=0.01424 \\
& \therefore \frac{q^{*}}{\frac{1}{\operatorname{Re}}\left(\nabla^{*}\right)^{2} T^{*}}=\frac{0.01424}{0.045}=0.3166 \\
& q^{*}<\left(\nabla^{*}\right)^{2} T^{*}
\end{aligned}
$$

Therefore the $2^{\text {nd }}$ term in the RHS of the dimensionless energy equation cannot be neglected.

According to the results of these analyses, for both 0.5 MW and 1.566 MW cases the argument of Kartabil [1] cannot be justified. This means that the dynamic similarity between the prototype CANDU-6 moderator tank and those of 1/4 scaled-down tank cannot be guaranteed for the power of 0.5 MW and 1.566 MW.

\section{Discussion and Summary}

As shown in the Figures on the temperature and velocity distributions of the moderator circulation for the CANDU-6 prototype tank and the 1/4 scaled-down tank, the velocity and temperature field patterns are quite different for the respective full power steady state operating condition. If one examines the velocity profile of the scaled-down case, the inlet jet front does not even reach the top of the tank, not does collide, unlike the prototype case, where two opposing jets collide a little at the right hand side of the top half of the tank as clearly shown in Figure 2(a). Also the temperature distribution in Figure 4(a) demonstrates the same result clearly. The authors think if this CFD analysis is correct, the scaling analysis based on the Ar number and the same dimensionless heat source distribution has a serious drawback. The authors are now examining if any important phenomena of the moderator circulation are left out in the scaling analyses, and one thing clearly said is the definition of the Ar number as the measure of the ratio of buoyancy to the local inertial force based on the temperature difference between the inlet and outlet temperature, $\Delta \mathrm{T}$, fails to properly account for the buoyancy force due to direct heating.

One result implying failure to reproduce the flow characteristics of the prototype CANDU-6 reactor is that the inlet jet front of the scaled-down CFD does not even reach to the top of the moderator tank. This shows that the current scaling based on Ar using $\Delta \mathrm{T}$ cannot account for this buoyancy driven phenomena as well as the inlet jet impingement phenomena properly for the MCF with the power of $0.5 \mathrm{MW}$. As the Re number similarity at the inlet jet nozzle was neglected in the similarity analysis, let alone the argument if it is a proper parameter for accounting for the jet development and collision phenomena, applying the scaling law based on Khartabil's approach may lead to a serious error in reproducing the important phenomena in MCF unless the validity of the key assumptions is carefully examined for the power supply capacity and inlet flow conditions.

As an way to confirm this validity an order of magnitude analyses was carried out and it was found that the assumption of neglecting viscous friction terms in the energy equation cannot be justified for the power levels of both 0.5 MW and 1.566 MW power supplies.

In conclusion, a porous media CFD analysis of the moderator circulation for the CANDU-6 reactor and the $1 / 4$ scaled-down test model revealed a serious discrepancy in the flow distribution as well as the temperature 
distribution. The possible reasons for this discrepancy were discussed, to figure out the reason for this mismatch an order of magnitude analyses were performed and neglecting the viscous friction term in the energy equation cannot be justified. Further research is thought to be necessary to confirm this result, i.e. if the scaling of the previous work [1] is justifiable by some other independent analyses.

\section{Acknowledgements}

This work was supported by the National Research Foundation of Korea (NRF) grant funded by the Korea government (Ministry of Science, ICT, and Future Planning) (No. NRF-2012M2A8A4025964).

\section{References}

[1] Khartabil, H.F., et al. (2000) Three-Dimensional Moderator Circulation Experimental Program for Validation of CFD Code MODTURC_CLAS. 21th CNS Nuclear Simulation Symposium.

[2] Rhee, B.W. and Kim, H.T. (2012) Derivation of the Scaling Criteria for a Small Scale CANDU Moderator Test Facility. Transactions of the KNS Spring Meeting, Jeju, 17-18 May 2012.

[3] Rhee, B.W., Kim, H.T., Park, S.K., Cha, J.E., Choi, H.-L. (2013) A Scaling Analysis of a CANDU-6 Moderator Tank Scaled-Down Test Facility. Proceedings of the 21st International Conference on Nuclear Engineering, ICONE21, 29 July-2 August2013, Chengdu.

[4] Gillespie, G.E., Moyer, R.G. and Thompson, P.D. (1982) Moderator Boiling on the External Surface of a Calandria Tube in a CANDU Reactor during a Loss-of-Coolant Accident. Proceedings of the International Meeting on Thermal Nuclear Reactor Safety, 29 August-2 September 1982, Chicago, USNRC, Report No. NUREG/CP-00, AECL-7604. 